Published in final edited form as:

Crit Care Med. 2016 August ; 44(8): e762-e764. doi:10.1097/CCM.0000000000001904.

\title{
Authors' response to Nunez-Rodriguez letter
}

\author{
Robert A Berg, MD, \\ Vinay M Nadkarni, MD, MS, \\ Children's Hospital of Philadelphia \\ Robert M Sutton, MD, MSCE, \\ Children's Hospital of Philadelphia \\ Michael Dean, MD, and \\ University of Utah \\ Murray Pollack, MD \\ Children's National Medical Center \\ Robert A Berg: bergra@email.chop.edu
}

Children's Hospital of Philadelphia, Dept of Anesthesia and Critical Care, 34th \& Civic Center

Blvd, 7th Floor South Tower, Rm 7C26, Philadelphia, Pennsylvania 19104, 267-426-3014

\section{Keywords}

cardiac arrest; Cardiopulmonary resuscitation; CPR; children; Outcomes

Dear Drs. Rodriguez-Nunez and Lopez-Herce,

Thank you for the kind comments ${ }^{1}$ about our report on the incidence and outcomes of cardiopulmonary resuscitation in the large academic PICUs from the Collaborative Pediatric Critical Care Research Network. ${ }^{2}$ We fully agree with your assumption that the incidence and outcomes may vary in other PICUs in the United States and throughout the world. Nevertheless, we are encouraged by the similar outcomes that you and others have reported from South European and Latin American PICUs, and from the American Heart Association's large multi-center Get With The Guidelines-Resuscitation registry. ${ }^{3-7}$

We are encouraged that most children in these studies had initially successful resuscitations resulting in return of circulation and that most of the children who survived to hospital discharge had favorable neurologic outcomes. However, there is still more information to be gained. In particular, the burden of poor outcomes following PICU CPR remains a large problem: many of the children with initial return of circulation either die or have poor neurologic outcomes. In addition, the children reported as having relatively "favorable" neurologic outcomes include children with substantial deficits in functional outcomes and quality of life. As recently emphasized by the Institute of Medicine, we need to develop effective and innovative approaches to prevent in-hospital cardiac arrests and to improve 
outcomes with more effective, patient-centric, hemodynamic-directed CPR and better postcardiac arrest care. ${ }^{8}$

Drs. Rodriguez-Nunez and Lopez-Herce note that there are quite limited data about the incidences and outcomes of pediatric CPR throughout much of the world. We share their concerns about the scarcity of PICU beds in many parts of the world, and the inherent consequence that in-hospital pediatric CPR is commonly provided in a non-PICU environment. Optimal outcomes depend on systems of care that limit the "no flow" period by prompt recognition and immediate treatment with chest compressions, provision of high quality CPR, and implementation of excellent post-cardiac arrest care. ${ }^{8}$ We believe that an ICU is the best setting for such prompt recognition, immediate CPR and excellent coordinated interdisciplinary care. ${ }^{2,7,9}$

\section{Acknowledgments}

Copyright form disclosures: Dr. Sutton received funding from Zoll Medical Corp. and disclosed other relationships (PALS writing group member; Pediatric Research Task Force member of the AHA's Get with the Guidelines Resuscitation Registry). His institution received funding from NICHD Career Development Award. Dr. Dean received support for article research from the National Institutes of Health (NIH). His institution received funding from the NIH. Dr. Pollack disclosed other support (University of Oklahoma for visiting professor/lecture) and received support for article research from the $\mathrm{NIH}$. He received funding: 1) He has had approximately 5 visiting professorships with travel funding and honoraria. He has had one expert consultancy during the period, 2) CPR Legal Firm, Philadelphia, and 3) Inova Health Care for Visiting Professor/Lecture. His institution received funding (This project was funded by the NICHD funded Critical Care Research Network during the time of the project).

\section{References}

1. Rodríguez-Núñez A, López-Herce J. The PICU: perhaps the "not so bad" place to suffer from cardiac arrest for children worldwide. Crit Care Med. 2016 in press.

2. Berg RA, Nadkarni VM, Clark AE, et al. Incidence and outcomes of cardiopulmonary resuscitation in PICUs. Crit Care Med. 2016; 44:798-808. [PubMed: 26646466]

3. Rodríguez-Núñez A, López-Herce J, García C, et al. Effectiveness and long-term outcome of cardiopulmonary resuscitation in paediatric intensive care units in Spain. Resuscitation. 2006; 71:301-9. [PubMed: 16989936]

4. Del Castillo J, López-Herce J, Cañadas S, et al. Cardiac arrest and resuscitation in the pediatric intensive care unit: A prospective multicenter multinational study. Resuscitation. 2014; 83:13801388. [PubMed: 25008138]

5. Moreno RP, Vassallo JC, Sáenz SS, et al. Estudio colaborativo multicéntrico sobre reanimación cardiopulmonar en nueve unidades de cuidados intensivos pediátricos de la República Argentina (Cardiopulmonary resuscitation in nine pediatric intensive care units of the Argentine Republic). Arch Argent Pediatr. 2010; 108:216-25. [PubMed: 20544136]

6. López-Herce J, Del Castillo J, Matamoros M, et al. Factors associated with mortality in pediatric inhospital cardiac arrest: a prospective multicenter multinational observational study. Intensive Care Med. 2013; 39:309-18. [PubMed: 23184036]

7. Berg RA, Sutton RM, Holubkov R, et al. Ratio of PICU versus ward cardiopulmonary resuscitation events is increasing. Crit Care Med. 2013; 41:2292-2297. [PubMed: 23921270]

8. Institute of Medicine of the National Academies. Strategies to improve cardiac arrest survival: A time to act. Washington, DC: National Academies Press; 2015.

9. Wolfe $\mathrm{H}$, Zebuhr C, Topjian AA, et al. Interdisciplinary ICU cardiac arrest debriefing improves survival outcomes. Crit Care Med. 2014; 42:1688-1695. [PubMed: 24717462] 